\title{
EU VOU PRA MARACANGALHA, EU VOU!
}

I'M GOING TO MARACANGALHA, I'M OFF!

\author{
MEGMÉCIA PRAZERES BOAVENTURA ${ }^{1}$ \\ ARIÁDNE SCALFONI RIGO²
}

RESUMO: O caso de ensino apresentado se trata de uma situação real sobre o projeto Taboarte, criado e desenvolvido pelas mulheres artesãs de Maracangalha, na Bahia. As atividades do projeto prosperaram até o ano de 2014, quando a produção despencou devido ao fim da matéria prima na comunidade, a taboa. Para tentar contornar a situação, as artesãs compraram a taboa de outros locais, porém essa solução não se mostrou vantajosa. Desanimadas, as mulheres de Maracangalha se viram numa situação emblemática em busca, novamente, de solução para os problemas enfrentados na comunidade. O objetivo central é levar o aluno a examinar os desafios enfrentados e a buscar soluções para os problemas vivenciados pelas artesãs, refletindo sobre economia solidária, desenvolvimento local e sentidos do trabalho. Os dados foram obtidos através de entrevistas semiestruturadas com os principais atores envolvidos direta e indiretamente com o projeto Taboarte. $\mathrm{O}$ caso apresenta a história da comunidade; coloca Anália e outras mulheres de Maracangalha como protagonistas do caso; relata os principais desafios que surgem ao longo do projeto bem como seus pontos fortes. As notas de ensino foram construídas no sentido de orientar a aplicação do caso e a condução dos debates, trazendo um amparo conceitual a cerca das questões propostas.

Palavras-chave: economia solidária; autogestão; desafios; desenvolvimento local.

ABSTRACT: This teaching case portrays a true story about the Taboarte project, created and developed by the artisan from Maracangalha, Bahia. Their activities thrived until2014, when the production plummeted due to the lack of the raw material in the community, the 'taboa'. As an attempt to get over the situation, the artisans decided to buy the 'taboa' from other places, however this solution was not effective. Discouraged, they found themselves again in an emblematic position in search of solution to the usual problems faced by the community. The main goal of this case is to lead the student to examine the challenges faced by the project and to seek solutions to those problems experienced by the artisans, reflecting on solidarity economy, local development and senses of work. The data were obtained through semi-structured interviews with the main actors directly and indirectly involved with the Taboarte project. The case presents the history of the community; Puts Analia and other women of Maracangalha as protagonists of the case; It reports on the main challenges they face throughout the project as well as their strengths. The teaching notes were built in order to guide the application of the case and its debates leadings, bringing a conceptual support on the proposed issues.

Keywords: solidary economy; self management; challenges; local development.

\footnotetext{
Data de submissão: 19/02/2018 Data de aceite: 06/06/2018 Data de publicação: 18/09/2018

${ }^{1}$ Graduada em Administração pela Universidade Federal da Bahia(2017).

${ }^{2}$ Professora da Escola de Administração (UFBA).
} 


\section{INTRODUÇÃO}

Após o fechamento da usina Cinco Rios, suas instalações foram abandonadas e a antiga represa que abastecia a fábrica se tornou solo fértil para vários tipos de vegetações aquáticas, um grande brejo. Assim, a taboa, planta aquática de grande adaptabilidade, dominou essa área passando a ser vista como uma "praga" pelos moradores. Devido ao seu alto teor inflamável, as queimadas da taboa eram frequentes, causando poluição do ar e grande transtorno para a comunidade.

Frente aos problemas da poluição do ar e da falta de emprego na comunidade, Anália, aos 41 anos, se via perto do dia em que teria que tomar uma decisão que deveria mudar sua vida. Ela estava entre "a cruz e a espada", como diria sua avó, Dona Rosa, de 83 anos, também nascida e criada no povoado. Anália, que amava muito sua comunidade, tinha uma decisão a tomar: deveria ir embora para Salvador tentar uma vida nova, como muitos outros fizeram, ou deveria ficar e buscar uma alternativa ali mesmo em Maracangalha? Com essa dúvida latejando em sua cabeça, ela foi buscar conselhos com amigos e parentes. É quando Raquel, sua confidente e amiga de infância, a aconselhou "pegue seu filho e vá pra Salvador, Anália. Essa comunidade e essa taboa não têm jeito. Só vai piorar e causar mais problemas pra todo mundo". Raquel não era tão sonhadora como Anália nem morria de amores por sua comunidade. Ela acreditava que nada mudaria por ali, e que qualquer tentativa de melhora seria perda de tempo. Por isso sempre esperava por uma oportunidade para abandonar o povoado.

Naquela tarde, como sempre fazia após o almoço, Anália foi para a porta de casa observar a rua. Sentou-se sozinha perdendo-se em devaneios. Fixou o olhar para a deserta Rua do Cruzeiro e assistiu uma rajada de vento carregar em sua direção uma palha seca de taboa. Ela apanhou a palha errante entrelaçando-a entre os seus dedos, dizendo em voz baixa para si mesma "O que farei com você?". Dando asas à sua imaginação, Anália então viu naquela palha de taboa o formato de uma flor e, levantando-se esperançosa num rompante, pensou: a taboa tem jeito! Foi assim que decidiu seguir o seu coração e não os conselhos da amiga Raquel. Naquela mesma noite saiu de porta em porta convidando as mulheres de todas as idades do povoado a se encontrarem na Praça Dorival Caymmi, com a promessa de uma solução para a taboa. Rapidamente, pouco antes da "novela das sete", um aglomerado de mulheres escutava Anália atentamente. Agora com o apoio das mulheres da comunidade, Anália saiu pelas cidades da redondeza em busca de apoio e informação, e assim a solução para a praga local começou a surgir: pelas mãos das mulheres de Maracangalha, a taboa viraria artesanato.

\section{EU VOU PRA MARACANGALHA, EU VOU!}

Para chegar ao povoado de Maracangalha, o único meio de transporte disponível é o rodoviário. É possível encontrar na região quem ainda chame a comunidade de "Cinco Rios", um legado da antiga usina de cana de açúcar. Maracangalha fica localizada a $60 \mathrm{~km}$ da capital baiana e possui pouco mais de dois mil habitantes. Logo na entrada do povoado, à beira da BA-512, o visitante se depara com duas pequenas chaminés de tijolos, onde se lê em letras garrafais: MARACANGALHA, um sinal de que se está no caminho certo. Cerca de um quilometro mais à frente, é possível ver os trilhos da antiga ferrovia que corta a cidade, e 
as primeiras casas do povoado logo surgem. À esquerda deste ponto, se encontram as ruínas da antiga usina, onde ainda é possível ler na fachada do prédio: "CINCO RIOS". Ao fundo, acompanhando as ruínas da fábrica, duas grandes chaminés dominam a paisagem e pouco se vê da antiga represa ao lado. Mais adiante, a bela e famosa praça em formato de violão, Dorival Caymmi, dá as boas-vindas aos visitantes. Dorival Caymmi representa um personagem importante para a comunidade, porque, graças a ele, em 1956 ela ficou conhecida nacional, e até internacionalmente, quando virou tema de uma de suas canções, a famosa: "Eu vou pra Maracangalha". A partir dessa pracinha, o povoado se destrincha em pequenas ruas e vielas que levam até a igreja de Nossa Senhora da Guia, fundada em 1933.

A pacata comunidade é um distrito da cidade de São Sebastião do Passé, na Bahia, tendo sido formada a partir da instalação de uma usina de açúcar conhecida por "Cinco Rios", em 1912. A usina funcionou na comunidade por 75 anos e durante todo esse período foi responsabilizada, pelos moradores, pela prosperidade do povoado. Em 1987, porém, a usina fechou definitivamente as portas, gerando desemprego em massa no povoado e obrigando parte dos trabalhadores a abandonarem seus lares em busca de outras oportunidades. No entanto, muitos moradores insistentes permaneceram em Maracangalha e passaram a viver da agricultura familiar.

Não existe consenso quanto à origem do nome Maracangalha, mas a população local acredita que no tempo dos antigos engenhos, bandos de ciganos que passavam pela região constantemente, ao prepararem os animais para retomarem as suas viagens, gritavam "amarra a cangalha!". Os escravos locais, para zombarem dos ciganos, deturparam a expressão e gritavam "Marracangaia"! Mais tarde a expressão se tornou "Maracangalha", dando nome ao povoado que ali surgiu.

\section{EU VOU DE CHAPÉU DE PALHA, EU VOU!}

Pela determinação, dedicação e cumplicidade, as Maracangalhenses chamaram a atenção da Coelba, da Área de Proteção Ambiental de Joanes-Ipitanga - APA Joanes e do Sebrae Bahia,e, em pouco tempo, novas personagens apareciam em Maracangalha. A garra dessas mulheres cativou essas e outras instituições de apoio e a taboa então deixou de ser "praga" para virar solução.

E assim surgiu o projeto Taboarte, um empreendimento autogerido de economia solidária com o intuito de controlar o problema ambiental e, de quebra, gerar renda para as mulheres e suas famílias. O projeto iniciou suas atividades em 2005 com tentativas de criação de peças e vários treinamentos para as futuras artesãs. Entretanto, só foi concretizado em 2008, quando as peças começaram a ser vendidas para além dos limites do vilarejo. Durante os períodos dos treinamentos, Anália admirava a facilidade com que as mulheres manuseavam a taboa e criavam inúmeras peças de artesanatos. Com o passar do tempo, as artesãs foram adquirindo maior habilidade e gosto pelo trabalho, e passaram a conquistar importantes grandes clientes e admiradores. E inúmeras foram as feiras de negócios e exposições que elas participaram.

Apesar de todo o sucesso, o Projeto Taboarte também lidava com alguns problemas na comunidade que preocupava Anália e suas companheiras: a falta de um espaço físico próprio 
e a falta de apoio de algumas pessoas da comunidade. Ambas as dificuldades foram se tornando críticas com o passar do tempo e culminaram em 2014 quando as artesãs se viram na situação mais complicada já enfrentada pelo projeto. De acordo com Dona Rosa, avó de Anália, o fato lembrou bem o tempo em que a "Cinco Rios" fechou suas portas na comunidade. A barragem que segurava a água da antiga represa rompeu, deixando escoar toda a água que alimentava a taboa. Sem barreiras, as águas das chuvas não eram mais armazenadas, secando a vasta área onde crescia generosamente a taboa. A matéria prima que nutria o trabalho das artesãs acabou tão de repente...

\section{EU VOU CONVIDAR ANÁLIA, EU VOU!}

Quando as moradoras de Maracangalha iniciaram com a produção dos artesanatos elas não faziam muita ideia de onde o projeto e suas peças chegariam. Das pequenas feiras na cidade de Candeias e São Sebastião do Passé, suas produções chegaram a ser comercializadas pela Le Lis Blanc, na França. No Brasil, os seus principais clientes se encontravam no Rio de Janeiro, São Paulo, Minas Gerais, além da Bahia.

Anália e as mulheres do Taboarte conseguiram desenvolver inúmeras peças de artesanato a partir da taboa, como bolsas, flores e buquês, esteiras, jogos americanos, suplás de mesa, pufes, caixinhas, porta-jóias, chapéus, porta guardanapos, carteiras, colares, pulseiras, chaveiros e brincos. Uma das artesãs, Dalva, conta que o projeto não tinha problemas de escoamento "porque toda produção era feita sempre de forma calculada de acordo com as encomendas, e também a demanda era muito alta". Elas trabalhavam no estilo de produção enxuta. Apenas quando os produtos iriam ser expostos ou vendidos em feiras é que elas faziam as peças além das quantidades encomendadas, porém deviam ser em pequenas quantidades, Dalva explica que: "os produtos feitos por taboa não podem ser armazenados de qualquer maneira, e a gente não tinha um espaço físico destinado pra isso". O projeto não tinha local apropriado para estoque, e a fibra da taboa necessitava de cuidados específicos para não estragar.

No início do projeto, cerca de 100 mulheres, de faixa etária entre 16 a 90 anos, participaram da formação do grupo. Com o tempo, porém, Anália viu a maior parte de suas companheiras tendo prioridades diferentes e abandonarem o projeto. No final, ficaram apenas 35 colegas, e embora trabalhassem ativamente, os rendimentos mensais variavam entre $R \$ 200,00$ e $\mathrm{R} \$ 600,00$ para cada uma. Elas não dispunham de um valor fixo, já que toda a renda era com base na produção, uma média de 500 peças mensais. Anália recorda que a falta de salário fixo, suficiente para manter toda uma família, foi para algumas um motivo de desmotivação, as quais decidiram sair do grupo e buscar novas alternativas fora da comunidade. Esse foi o caso de Lúcia, mãe de 03 filhos: "por causa da fonte de renda, eu preferi trabalhar numa indústria porque lá a gente já tem aquele dinheirinho fixo, um salário e os direitos garantidos". E também o caso da jovem Amanda: "fiz o curso, mexi com o material, mas não levei à frente. Eu saí porque eu tive que ir trabalhar numa empresa de refeição". Para as mulheres que continuaram no projeto, porém, esse não era um grande problema, pois o viam como um espaço que lhes proporcionava prazer e bem-estar. Dona Rosa diz que: "trabalhando com artesanato você pratica uma terapia onde você desenvolve tudo de bom. Você conhece pessoas diferentes, você mexe com o seu subconsciente. Enfim, você se sente 
uma outra pessoa". Dona Josefa de 53 anos diz que não largaria o artesanato "porque é algo que a gente gosta de fazer. Porque eu não tinha ideia do que era, né?! Eu não sabia fazer nada de artesanato, e quando eu fui chegando lá, eu fui aprendendo com as outras mulheres e fui desenvolvendo, e aí passei a gostar e hoje faz parte de mim".

A gestão do projeto era feita pelas próprias artesãs que também se ocupavam das funções relativas à produção. Anália era a coordenadora do projeto, Dalva a vice-coordenadora, Dona Josefa era a tesoureira e, Dona Ana, a diretora comercial. As outras artesãs também apoiavam as demais funções administrativas, como representantes de vendas e secretariado. A partir desse processo autogestionário, as artesãs eram donas do próprio empreendimento e dos meios de produção. De forma colaborativa, trabalhavam em harmonia buscando enfrentar os desafios que se apresentavam.

Anália e Dalva, entretanto, reconhecem que o sucesso do projeto não se deu por acaso. Afortunadamente elas contaram com o apoio de instituições de peso que se tornaram parceiros do projeto. Segundo elas, todos esses parceiros tiveram suas parcelas de participação no desencadear do Taboarte. As artesãs recebiam capacitações pelas instituições interventoras, seja para melhor lida com o manejo ambiental, a fim de evitar o desmatamento e a extração incorreta da fibra, seja para melhor gerenciar o projeto através de oficinas nas áreas gerenciais. O Sebrae Bahia foi uma das instituições que acompanhou de perto o trabalho dessas mulheres e as capacitou visando melhorias quanto ao processo produtivo, autogestão, formação de preços, design e redesign de peças, qualidade, entre outros, além da busca por clientes potenciais através das rodadas de negócios.

\section{SE ANÁLIA NÃO QUISER IR, EU VOU SÓ!}

Como em qualquer outra organização, o projeto também enfrentava internamente alguns problemas que preocupavam as artesãs. Com o decorrer do tempo, esses pequenos empecilhos foram tomando dimensões maiores e conseguiram desacelerar a produção. Durante os dez anos de trabalho duro, Anália e suas companheiras conseguiam contornar esses variados obstáculos de forma sutil e corajosa.

O clima se tornava vilão dos artesanatos quando, na época das chuvas, a falta de sol para secar a taboa estragava a fibra e prejudicava a produção. Dona Josefa conta que nos dias chuvosos, a preocupação e agitação de todas elas eram perceptíveis. Isso porque após as colheitas, as fibras eram postas para secar por três dias no sol quente, e depois de secas, descansavam por mais dois dias na sombra, porém longe de umidade. Somente a partir de então, é que a taboa estava pronta para ser manipulada e transformada. Contudo, nos dias de chuva, muita fibra se estragava e era jogada fora, recorda dona Josefa ainda com tristeza.

A falta de um espaço físico próprio se tornava outro obstáculo para as artesãs. Elas se reuniam e faziam uso do espaço da AMAM (Associação dos Moradores Amigos de Maracangalha), que dividia o local com outros eventos da comunidade e não tinham a exclusividade do uso. Quando o espaço era solicitado para outros tipos de eventos como reuniões, casamentos, aniversários, Anália, Dalva e as demais mulheres do Taboarte tinham que retirar todo o material do local e o depositavam na casa de Dona Ana que morava mais perto. 
Uma parte da comunidade, todavia, não acreditava no trabalho das artesãs e não lhes apoiava, o que se consistia em mais um obstáculo. E, para a tristeza de Anália, uma delas era a sua amiga Raquel. Raquel, dizem que por orgulho, nunca aceitou o convite de Anália para fazer parte do grupo de artesãs. A resposta era sempre a mesma: "obrigada, mas estou bem melhor aqui, e ainda mais, tem muita gente lá que não me agrada. Não nasci para brincar de artesanato, Anália".

Para as outras artesãs a falta de apoio de alguns moradores da comunidade se manifestava de diversas formas desde chamá-las de "doidas" quando passavam pelas ruas do povoado carregando na cabeça os fardos da taboa recém extraída, até atear fogo nas plantas. 0 terreno onde as taboas cresciam pertencia aos herdeiros das ruínas da antiga usina Cinco Rios. O local, entretanto ficou aberto e abandonado desde o fechamento da indústria, logo as artesãs disputavam as taboas com outros interessados da comunidade. Às vezes as plantas eram incendiadas para dar espaço a animais como gado e cavalos, ou extraídas para servirem de alimento para os mesmos. Anália acredita que algumas ações erosivas, de alguns moradores no alagado, acelerou e agravou o processo do rompimento da barragem. Essa falta de cumplicidade desses moradores foi suficiente para transformar pequenos desafios em obstáculos complicados para ultrapassagem.

Frente a estes obstáculos e diante daquele que veio a se tornar o pior de deles - o fim da taboa com o rompimento do alagado - as artesãs se viram na pior situação desde o fechamento da usina Cinco Rios anos atrás. Sem barragem e sem taboa, elas tentaram satisfazer a elevada demanda por seus produtos pagando pessoas da comunidade para buscar taboa em outras localidades perto de Maracangalha. No início Anália se animou e imaginou que essa alternativa atenderia às necessidades da produção. No entanto, com a falta das chuvas, as lagoas próximas também foram secando o que elevou o preço da taboa diante da sua escassez. E foi por todos esses problemas que o Taboarte, no final de 2015, encerrou suas atividades.

Anália, então, assistiu os seus sonhos e os de suas companheiras caírem por terra. Depois de algumas noites insone, Anália se viu novamente diante da mesma questão inicial que a fizera sair do lugar e começar tudo: seria este o momento de abandonar Maracangalha?

\section{SUGESTÕES DE QUESTÕES PARA DEBATE E ANÁLISE DO CASO:}

1. A partir do caso apresentado de economia solidária, aponte as características facilitadoras e os desafios comuns a esse tipo de empreendimento.

2. Dado o caso do projeto Taboarte, você considera que esse empreendimento de economia solidária se mostrou uma alternativa viável ao modo de produção capitalista? Justifique.

3. Relacione a noção de desenvolvimento local, economia solidária e o caso do Projeto Taboarte na comunidade de Maracangalha?

4. Entre o trabalho na usina Cinco Rios e no projeto Taboarte, é possível refletir sobre o processo de ressignificação do trabalho para as mulheres da comunidade. Apresente a noção de ressignificação do trabalho e o relacione com o caso do projeto Taboarte. 


\section{NOTAS DE ENSINO}

\section{FONTE DE DADOS DO CASO E A REAL SOLUÇÃO ENCONTRADA PELAS ARTESÃS}

O caso apresentado se trata de uma situação real e foi o objeto de estudo do Trabalho de Conclusão de Curso - TCC, de uma das autoras, apresentado em março de 2017 à Escola de Administração da Universidade Federal da Bahia. O projeto Taboarte prosperou até o ano de 2014, quando a produção despencou devido ao fim da taboa. Para tentar contornar a situação as artesãs tentaram comprar a matéria prima de outros locais, porém essa solução não se mostrou eficaz, mas desvantajosa. Desanimadas, algumas artesãs abandonaram o povoado e foram tentar a vida em outras cidades. As que permaneceram voltaram a se dedicar totalmente à casa e à família; e outras ainda fazem poucas peças de artesanato, e vendem por conta própria, quando encontram interessados, porém com outro material.

\section{OBJETIVOS DE APRENDIZAGEM E ASPECTOS PEDAGÓGICOS}

A aplicação deste caso de ensino foi pensada para refletir diferentes contextos territoriais que buscam soluções endógenas para problemas socioeconômicos. Sugerimos que o foco do exercício a partir da leitura do caso seja a busca pelos estudantes por soluções que considerem a história da comunidade, seu contexto e seus protagonistas. A nosso ver, a aplicação deste caso é pertinente em disciplinas de Administração voltadas para análises de organizações coletivas como cooperativas, associações, ONGs etc. É também adequado em disciplinas que envolvam gestão pública e poder local. Disciplinas como Gestão Social e Economia Solidária são espaços adequados para que este caso sirva de base para o trabalho final, tendo em vista que sua solução exige levantamentos, estudos e um processo criativo que demanda tempo. A aplicação deste caso como trabalho final de disciplina possibilita, ainda, que vários grupos apresentem diferenciadas soluções e planos de ação que podem ser comparados e discutidos.

Como sugestão, o caso poderá ser aplicado em sala através do seguinte processo:

1. Dividir a sala em grupos de 03 a 05 alunos;

2. Apresentar aos alunos os objetivos da atividade: analisar o caso, discutir entre si os problemas e possíveis alternativas de soluções, também baseadas em leituras e conhecimentos prévios já adquiridos no curso;

3. Apresentar a importância e relevância da aplicação do método do caso de ensino em sala de aula. Conforme declara Heath (2006, apud CAMPOS; ALMEIDA, 2014, p.59) a sua importância consiste principalmente porque a análise de um caso é capaz de promover o desenvolvimento de habilidades de análise e pensamento crítico dos alunos, incentiva a tomada de decisão. O método do caso ainda ajuda no desenvolvimento de técnicas de julgamento entre distintos cursos de ação, na elaboração de pressupostos e inferências, na apresentação de pontos de vista, na escuta ativa, no entendimento da perspectiva do outro, bem como conecta a teoria à prática; 
4. Distribuir uma cópia do caso por grupo;

5. Conceder um tempo médio para leitura de 20 a 30 minutos, mais uma mesma média de tempo para as discussões, análises e elaboração de soluções às perguntas-guia em grupo;

6. Solicitar que os grupos apresentem à turma suas soluções encontradas;

7. Identificar os grupos com soluções similares e unificá-los;

8. Incentivar os grupos com opiniões diferentes a debaterem entre si os porquês de suas opiniões, de acordo com seus argumentos formulados a partir de leituras e conhecimentos prévios;

9. Finalizar solicitando aos alunos que façam um breve comentário a respeito do método do caso utilizado pelo professor explanando seus prós e contras.

\section{SUGESTÕES DE RESPOSTAS PARA AS QUESTÕES PROPOSTAS NO CASO}

\section{A partir do caso apresentado de economia solidária, aponte as características facilitadoras e os desafios comuns a esse tipo de empreendimento.}

Assuntos como economia solidária, gestão social, terceiro setor, associativismo e cooperativismo são exemplos dos rumos que os debates podem tomar em sala de aula. Neste sentido, estudos como os encontrados em França Filho e Laville (2004), França Filho (2007 e 2008), Tenório (1998 e 2012) podem ser interessantes para oferecer elementos teóricos e metodológicos para refletir o caso em si e as soluções para os desafios ou obstáculos enfrentados pelas protagonistas de Maracangalha. Para uma discussão histórica da economia solidária no Brasil, recomendam-se as leituras de Santos e Rodrigues (2005) e de Singer (2002 e 2005). Nestas leituras, várias formas de organizações coletivas são vistas como alternativas para minimizar a degradação do trabalho. Como argumenta França Filho (2002), a própria expressão "economia solidária" indica "experiências organizacionais inscritas em novas formas de construções coletivas e na ênfase na confiança e reciprocidade entre os indivíduos de uma localidade".

Com relação ao projeto taboarte, algumas características facilitadoras podem ser consideradas como a aceitação do mercado; o apoio de órgãos como o SEBRAE, COELBA, e APA Joanes, participações em várias feiras de negócios, produtos de qualidade, mão de obra qualificada, clientela fidelizada, matéria prima de baixo custo, união entre as artesãs, entre outras. Como desafios, podemos considerar a falta de apoio de uma parte da comunidade, a ausência de propriedades onde crescia e onde armazenar a taboa, assim como o despreparo para lidar com questões do clima, na dependência de um único tipo de matéria prima, e a falta de planejamento para lidar com problemas de longo prazo, como a possível extinção da taboa na região. 


\section{Dado o caso do projeto taboarte, você considera que esse empreendimento de economia solidária se mostrou uma alternativa viável ao modo de produção capitalista? Justifique.}

De acordo com Paul Singer (2008), a Economia Solidária é tida como um modo de produção que se caracteriza pela igualdade de direitos, e onde os meios de produção são de posse coletiva dos que trabalham com eles. Sendo essa a característica central da Economia Solidária, os empreendimentos de economia solidária são geridos pelos próprios trabalhadores coletivamente e de forma inteiramente democrática, quando cada sócio e membro do empreendimento têm direito a um voto nas tomadas de decisões.

Singer (2000) afirma ainda que a economia solidária é parte de um projeto organizacional socioeconômico regido por princípios contrários ao do liberalismo capitalista. Para ele, a economia solidária está alicerçada em três pilares básicos: regulação econômica, participação nos lucros e autogestão do trabalho. Singer também propõe que a economia deveria ser sempre solidária acima de competitiva, a fim de se ter uma sociedade justa e igualitária, o que significa dizer que "os participantes na atividade econômica deveriam cooperar entre si em vez de competir" (SINGER, 2002, p. 09).

A economia solidária compreende diferentes tipos de organizações sociais, não se restringindo a nenhum tipo exclusivo de "empresas". Podendo ser essas organizações de economia solidária: associações, cooperativas, empresas autogestionárias, redes de cooperação, complexos cooperativos, dentre outros (SOUSA; NEVES, 2011). Trata-se de um modo de produção alternativo ao tradicional, que segundo Singer (2002), seus princípios básicos se assentam sobre a propriedade coletiva ou associada do capital e o direito à liberdade individual. Mais adiante o autor afirma que a solidariedade e a igualdade são o resultado natural desse modo de produção baseado nesses princípios, o que exige mecanismos estatais de repartição solidária da renda (2002, p. 10).

Singer (2002) supõe que a divergência básica entre a economia solidária - autogestão - e a economia capitalista - heterogestão - esteja diretamente ligada ao modo como as empresas são administradas. Para ele, a heterogestão é identificada principalmente pela verticalização da informação e do conhecimento, onde:

A heterogestão - economia capitalista - é formada por níveis hierárquicos sucessivos de autoridade, entre os quais as informações e consultas fluem de baixo para cima e as ordens e instruções, de cima para baixo. Os trabalhadores do nível mais baixo sabem muito pouco além do necessário para que cumpram suas tarefas, que tendem a ser repetitivas e rotineiras. À medida em que se sobe a hierarquia, o conhecimento sobre a empresa se amplia porque as tarefas são cada vez mais menos repetitivas, e exigem iniciativa e responsabilidade por parte do trabalhador. Nos níveis mais altos, os conhecimentos sobre a empresa deveria ser em tese total, já que cabe a seus ocupantes tomar decisões estratégicas sobre os seus rumos futuros. (SINGER, 2002, p.17). 
Já quanto a autogestão, Singer indica a horizontalização das informações, conhecimentos e responsabilidades, como sendo suas características principais, onde cada trabalhador é responsável por um todo:

Pelo visto, a autogestão exige um esforço adicional dos trabalhadores na empresa solidária: além de cumprir as tarefas a seu cargo, cada um deles tem de se preocupar com os problemas gerais da empresa. Esse esforço adicional produz ótimos resultados quando se trata de envidar mais esforços para cumprir um prazo, eliminar defeitos de um produto ou para atingir algum objetivo que todos desejam. O gato de todos ficarem a par do que está em jogo contribui para a cooperação inteligente dos sócios, sem necessidade de que sejam incentivados por competições para saber quem é o melhor de todos (SINGER, 2002, p. 19).

Dessa forma, fica possível declarar que a participação dos trabalhadores nos processos de tomada das decisões e retenção de conhecimentos a respeito da organização onde esteja inserido é um dos pontos cruciais que diferencia a autogestão da economia solidária, da heterogestão da economia capitalista.

\section{Relacione a noção de desenvolvimento local, economia solidária e o caso do Projeto Taboarte na comunidade de Maracangalha.}

Diretamente relacionada à ideia de desenvolvimento local, está a de comunidade, pois, de acordo com Martinelli e Joyal (2004, p. 53), "o desenvolvimento local reforça as comunidades, dinamizando as suas potencialidades". Tais potencialidades passaram a se destacar não somente como fontes promotoras do desenvolvimento, mas também como forças de onde este desenvolvimento poderia partir. No entanto, o processo de "mobilização das energias" locais, não se dá, na maioria das vezes, sem um considerável esforço externo.

Experiências de desenvolvimento local, tanto européias quando latino-americanas, como salienta Dallabrida (2000), resultaram não somente de injeção de recursos financeiros, mas também da potencialização de recursos do próprio local. Neste aspecto, o Estado tem um papel importante de fornecer meios para a mobilização dessas energias sociais (Ribeiro, Mendonça e Guedes, 2002; Martinelli e Joyal, 2004). Ressalta-se ainda, nestes processos, a preocupação com fatores que não são exclusivamente de caráter econômico, mas também com aspectos sociais e os culturais, os quais são vistos como facilitadores do desenvolvimento local (Llorens, 2001).

Em resumo, processos de desenvolvimento local devem ser capazes de mobilizar energias sociais no território e elevar "as oportunidades sociais, a viabilidade econômica e as condições de vida da população". Buarque (1999) reforça que,

Desenvolvimento local é um processo endógeno registrado em pequenas unidades territoriais e agrupamentos humanos capaz de promover o dinamismo econômico e melhoria da qualidade de vida 
da população. Representa uma considerável transformação nas bases econômicas e na organização social em nível local, resultante da mobilização das energias da sociedade, explorando as suas capacidades e potencialidades específicas (Buarque, 1999, p. 23-24).

Grande parte das diferentes ações e intervenções nos territórios se baseia na constituição de Empreendimentos de Economia Solidária (EES) dos mais variados tipos, tais como: cooperativas populares de diferentes ramos, associações de moradores, e/ou de produtores, grupos de trabalho como os de artesões, catadores de lixo, mulheres, jovens entre outros. Na percepção de Singer (2005), a economia solidária engloba essa diversidade de empreendimentos e organizações sociais dos setores marginalizados da economia. Segundo França Filho (2002, p. 13), os empreendimentos de economia solidária são "experiências que se apóiam sobre o desenvolvimento de atividades econômicas para a realização de objetivos sociais".

As práticas em economia solidária no Brasil estão intimamente relacionadas, em maior ou menor grau, com a promoção do desenvolvimento de territórios. No entanto, se referem a um tipo de desenvolvimento endógeno que considere soluções coletivas e privilegie novas formas de regular as relações econômicas e sociais. Esta maneira de conceber as ações em economia solidária é entendida por França Filho (2007) como uma "via sustentável-solidária do desenvolvimento", que parte da premissa de que as soluções para o desenvolvimento dos territórios são coletivas "baseadas em novas formas de regulação das relações econômico-sociais".

Com relação ao caso do projeto Taboarte em Maracangalha é possível perceber essa ajuda externa quando órgãos apoiadores se sensibilizaram a ajudar as mulheres desta comunidade, como é o caso da Coelba e do Sebrae Bahia. Outro ponto a respeito do desenvolvimento deste local está na constituição de Empreendimentos de Economia Solidária (EES), como foi o caso do próprio projeto que, mesmo informal, criou um grupo produtivo baseado na autogestão, ações coletivas e equidade nas relações de trabalho ao longo da sua existência. O processo de desenvolvimento local em Maracangalha, mesmo que por um tempo determinado, possibilitou às mulheres dessa comunidade tomar a centralidade do seu papel na comunidade. Sentimentos como pertencimento e empoderamento das maracangalhenses se manifestaram dando o tom do projeto e do processo de trabalho.

\section{Entre o trabalho na usina Cinco Rios e no projeto Taboarte, é possível refletir sobre o processo de ressignificação do trabalho para as mulheres da comunidade. Apresente a noção de ressignificação do trabalho e o relacione com o caso do projeto Taboarte.}

A espécie humana, desde sua origem, se desenvolve a partir de técnicas que garantam sua subsistência e sobrevivência, e vem realizando essas práticas sempre buscando maior comodidade e eficiência nos seus atos (Campos e Saraiva, 2014). Assim enquanto vivendo em sociedade, necessita produzir sua riqueza material, e para que essa produção aconteça, faz-se então necessário que o homem transforme a natureza em valores de uso. Nesse 
processo, em meios de subsistência ou de produção, o homem atua de forma consciente e intencional, controlando e executando sua ação através de seus membros corpóreos contra os elementos da natureza. Esse processo de transformação dá-se através do trabalho.

O trabalho, todavia, constitui uma representação social e histórica, que veio, e vem, sofrendo transformações e ressignificações ao longo do tempo, mas sempre direcionando a vida, tanto em sociedade, quanto no plano individual (Campos e Saraiva, 2014). Ferreira e Barbosa (2014) apresentam o trabalho como uma categoria universal imprescindível em qualquer formação social, corroborando com Morin (2001), quando a autora identifica o trabalho como "uma atividade que se inscreve no desenvolvimento de uma sociedade" (Morin, 2001, p.16); por isso o trabalho deve por consequência respeitar as regras relativas ao dever e ao saber viver em sociedade, inspirado nos valores éticos, espirituais e morais. 0 que seria dizer que o trabalho deve ser realizado de forma socialmente responsável (Morin, 2001). Entretanto, o trabalho em si apresenta sentidos e significados diversos de forma multifacetada, composto de variáveis tanto sociais quanto pessoais, as quais estão constantemente sendo pesquisadas e identificadas em todo o mundo por diversos autores de diferentes áreas (Andrade, Tolfo e Dellagnelo, 2012).

Pesquisas realizadas por diversos autores, entre eles Morin (2001), Morin, Tonelli e Pliopas (2007) e o grupo MOW (1987, citado em Morin, 2001), conseguiram identificar que o sentido do trabalho está além daquele de "ganha pão". Através da pergunta "se você tivesse bastante dinheiro para viver o resto da sua vida confortavelmente sem trabalhar, o que você faria com relação ao seu trabalho?", de acordo com Morin (2001), mais de $80 \%$ das pessoas entrevistadas responderam que continuariam trabalhando ainda assim. Segundo a autora, as principais razões para que um indivíduo, mesmo com condições financeiras satisfatórias, desejasse ainda continuar trabalhando são: para se relacionar com outras pessoas, para ter o sentimento de vinculação, para ter algo que fazer, para evitar o tédio e para se ter um objetivo na vida (Morin, 2001).

A ressignificação se apresenta a partir da diferença entre as formas de trabalho. Na usina Cinco Rios, o trabalho ou melhor, o emprego, se resumia em executar tarefas desenhadas e supervisionadas pelos gestores da empresa, nos moldes capitalistas. $O$ trabalho no projeto Taboarte possibilitou às maracangalhenses serem as gestoras do próprio empreendimento, autogerido, voltado para os moldes da economia solidária. No taboarte não existia uma renda fixa nem horários rígidos de trabalho. Cada uma recebia de acordo com a produção de cada mês. Existia uma autonomia nesta forma de trabalho e, ao mesmo tempo, uma insegurança em relação a remuneração tendo em vista as incertezas inerentes a esse tipo de organização.

Os sentimentos de pertencimento que as artesãs desenvolveram pelo projeto não fariam muitas delas trocarem o modo de produção artesanal por aquele industrial da antiga usina Cinco Rios, por diversos motivos. De acordo com elas: "trabalhando com artesanato você pratica uma terapia onde você desenvolve tudo de bom. Você conhece pessoas diferentes, você mexe com o seu subconsciente. Enfim, você se sente uma outra pessoa" (Entrevista, artesã e presidente do projeto Taboarte, fevereiro de 2017). Quando perguntadas a respeito dessa troca de modo de produção, as respostas foram variadas, porém sempre exaltando a 
vontade de continuar com o projeto, já que este proporcionava, acima de tudo, liberdade para elas.

O que é melhor você é independente não fica presa a indústrias, a salários, você mesmo faz o seu próprio salário dependendo da sua capacidade, então é muito melhor. Eu escolheria sem dúvida continuar e ficar com o projeto da taboa ou com qualquer projeto de artesanato já que além, da taboa, do produto de taboa, existe outra maneira da gente continuar a trabalhar com artesanato. (Entrevista, artesã e presidente do projeto Taboarte, fevereiro de 2017).

Percebe-se nessa fala uma rejeição do trabalho nos moldes de produção capitalista, abordados por Ferreira e Barbosa (2014). Para elas os resultados do processo de trabalho, passaram a ser transformados em valores de troca, voltados exclusivamente para geração de lucro. E a lucratividade, a partir do trabalho, alcançou um patamar superior aos da produção voltada para o atendimento das necessidades humanas.

Nessa ressignificação do trabalho, a partir do projeto Taboarte, para as artesãs, percebe-se ainda a presença efetiva de quase todas as seis características desenvolvidas por Morin $(1996,1997,2002)$, as quais dão sentido ao trabalho: a) É feito de forma eficiente e leva a alguma coisa; b) É intrinsecamente satisfatório; c) É moralmente aceitável; d) É fonte de relações humanas satisfatórias; e) Garante segurança e autonomia; e f) Mantém as pessoas ocupadas. Segundo ela, quanto mais positivamente as pessoas avaliarem o trabalho que desenvolvem, mais significado e sentido elas encontrarão nele (Bendassolli, Borges e Andrade, 2010). Singer (2002) prevê essa aceitação e sentimento de pertencimento por parte dos empreendedores solidários ao seu trabalho, quando ele afirma que as pessoas aprendem a não serem escravas do sistema nem a se submeterem a ordens alheias. Logo elas possuem melhores relacionamentos interpessoais e sociais e ganhos para a comunidade.

No entanto, no que diz respeito a garantia de segurança, no caso do projeto e em muitos empreendimentos solidários, torna-se uma questão crítica. A falta de recursos, deficiências na profissionalização da gestão e a dificuldade de obtenção de apoios mais duradouros são desafios, geralmente iniciais, que colocam em risco a continuidade e o amadurecimento das iniciativas tendo em vista que tudo isso leva a dificuldades de remunerar os atores envolvidos no processo. Como no caso do Taboarte, muitas mulheres deixaram de produzir e saíram do projeto diante das incertezas e dificuldades na remuneração. Ou seja, necessidades mais básicas e urgentes tendem a ser prioridade e a busca por salário fixo e certo, para muitas, é uma questão de sobrevivência.

\section{REFERÊNCIAS CITADAS NAS NOTAS DE ENSINO}

Andrade, S. P. C.; Tolfo, S. R.; Dellagnelo, E. H. L. (2012). Sentidos do Trabalho e Racionalidades Instrumental e Substantiva: Interfaces entre a Administração e a Psicologia. Revista de Administração Contemporânea, Rio de Janeiro, v. 16, n.2, 200-216. 
Buarque, S. C. (1999) Metodologia de planejamento do desenvolvimento local e municipal sustentável, 2 ed. IICA, Recife.

Campos, M; Saraiva, L. A. S. (2014).O trabalho, suas Representações e Sentidos: da Demissão à Recontratação de Trabalhadores. Revista Economia e Gestão - E\&G, PUC Minas, - v. 14, n. 36, jul./set. 2014.

Campos, R. D; Almeida, V. M. C. Método do caso: "não sei, não ..." enfrentando as barreiras à implantação do método. Revista Administração: Ensino e Pesquisa - Raep, Rio de Janeiro v. 15 n. 1 p. 43-72, jan./fev./mar. 2014.

Dallabrida, V. R. (2000) "Sustentabilidade e endogenização: novos paradigmas para o desenvolvimento regional", in Becker, D. F. e Bandeira, P. S. Desenvolvimento regional-local: determinantes e desafios contemporâneos, EDUNISC, Santa Cruz do Sul, p.187-228.

França Filho, G. C. (2002). Terceiro Setor, Economia Social, Economia Solidária e Economia Popular: traçando fronteiras conceituais. Bahia - Análise \& Dados, Salvador - Bahia, v. 12, n. 01, p. 09-19.

França Filho, G. C., Laville, J. L (2004). Economia solidária: uma abordagem internacional. Porto Alegre: Editora da UFRGS.

França Filho, G. C (2007). Teoria e prática em economia solidária: problemática, desafios e vocação. Porto Alegre: Civitas, v. 7(1), pp. 155-174.

França Filho, G. C (2008). A via Sustentável-Solidária no Desenvolvimento local. Salvador: Organizações \& Sociedade. v 15(45), pp. 219-232.

Llorens, F. A. (2001) "Novas políticas territoriais e funções da gestão local do desenvolvimento", in Desenvolvimento econômico local: caminhos para a construção de uma nova agenda política, BNDES, Rio de Janeiro, p.135-160.

Martinelli, D. P. e Joyal, A. (2004) Desenvolvimento Local e o papel das pequenas empresas, Manole, São Paulo.

Morin, E. M.(2001). Os sentidos do trabalho. Revista de Administração de Empresas, São Paulo, v. 41, n. 3, 8-19.

Morin, E. M; Tonelli, M. J.; Pliopas, A. L. V. O trabalho e seus sentidos. Psicologia \& Sociedade, 19, Edição Especial 1: 47-56, 2007.

Ribeiro, C., Mendonça, P. e Guedes, P. (2002) "Modelos organizacionais para o desenvolvimento local integrado e sustentável: o estudo de caso do SEBRAE/BA", Anais do 26을 Encontro da Anpad, 2002.

Santos, B. S., Rodríguez, C. (2005). Para ampliar o cânone da produção. In. Produzir para Viver: os caminhos da produção não capitalista. Rio de Janeiro: Civilização Brasileira.

Singer, P. (2002). Introdução à economia solidária. São Paulo: Perseu Abramo.

Singer, P. (2005). A recente ressurreição da economia solidária no Brasil. In. Santos, Boaventura de Sousa (org). Produzir para Viver: os caminhos da produção não capitalista. 2 ed. Rio de Janeiro: Civilização Brasileira, pp. 81-126. 
SINGER, Paul. ECONOMIA SOLIDÁRIA VERSUS ECONOMIA CAPITALISTA. São Paulo, 2008.

SOUSA, Adrianyce, e NEVES, Daniela. ECONOMIA SOLIDÁRIA: elementos para análise das políticas de geração de trabalho e renda. UnB. Brasília: 2011.

Tenório, F. G (2012).Gestão social, um conceito não idêntico? Ou a insuficiência inevitável do pensamento. In: Cançado; A. C.; Tenório, F. G.; Silva Jr., J. T. Gestão social: aspectos Teóricos e aplicações. ljuí: Unijuí. pp. 23-36.

Tenório, F. G (1998). Gestão social: uma perspectiva conceitual. Revista de Administração Pública, v.32(5), pp.7-23.

\section{REFERÊNCIAS COMPLEMENTARES PARA APROFUNDAMENTO}

Alencar, I. de. (1957). Afinal, Que é Maracangalha?. Revista Manchete. Acervo. Fevereiro de 1957.

Cattani, A. D. et al. (Orgs) (2009). Dicionário internacional da outra economia. Porto Alegre: Edições Almedina, pp. 208-213.

França Filho, G. C. (2006). A economia popular e solidária no Brasil. In: França Filho, G., Laville, J. L.; Magnen, J. P.; Medeiros, A.(org.). Ação Pública e economia solidária: uma perspectiva internacional. Salvador-Porto Alegre, EDUFRGS/EDUFBA.

Paiva, V. N. (1996). Maracangalha: Torrão de Açucar, Talhão de Massapê. São Sebastião do Passé, Bahia. 